\title{
Health help-seeking by men in Brunei Darussalam: masculinities and 'doing' male identities across the life course.
}

\begin{abstract}
Using data collected through semi-structured interviews and focus group discussions with 37 adult men living in Brunei Darussalam, this paper explores how masculinities and expectations about male roles across the life course influence men's perceptions, of and attitudes towards health and health help-seeking behaviour.

Bruneian men gave accounts that consistently spoke of a series of masculine roles and associated attributes and behaviours which mapped across the life course. Men described health and the steps that they had taken to protect their health in terms of responsibilities associated with being a breadwinner, provider of support for parents, role model and leader of the family. Whilst adherence to Bruneian norms about masculinity could obstruct men's engagement with health help-seeking, we also found that men mobilised their understanding of Bruneian masculinity such that it provided culturally legitimate way of engaging in health help-seeking.
\end{abstract}


We conclude by considering implications for further development of conceptualisations of masculinities, particularly responding to the call to consider Connell's theory of 'hegemonic masculinity' in the context of the Global South. We also consider the implications of the findings of this research for policy and practice in provision of health promotion and services in Brunei.

\section{Keywords}

Masculinities, Health, Health Help-seeking, Brunei, South Asia, Men

\section{Introduction}

Understanding how people manage their health and their motivations to access healthcare services is crucial to providing effective health education and to the development and delivery of health services (Rosenstock, 2005). It is well known that attitudes towards health and use of health services are gendered, such that typically, men use services less often than women, access them later and tend to do so in crisis or critical health need (Galdas et al, 2005; Addis \& Mahalik, 2003). Using data drawn from the first study of men's health and help-seeking undertaken in Brunei Darassalam, this paper explores men's attitudes, motivations and experiences of health service use. The study asked: How do Bruneian men define health and illness? And, what health help-seeking processes do they adopt? Answers to these questions 
guide our thinking in proposing how Connell's concept of Hegemonic Masculinities as applied to health be developed to better reflect the context of the Global South.

\section{Masculinities and health: applying theory in the global south.}

Since the mid-1980s there has been a surge of research interest in the field of men's health. The World Health Organization (2000) stated that “...this was initially driven by the need to establish the reasons behind men's poor health outcomes and their shorter life expectancy compared to women and also aimed to change policy and practices regarding men's health and wellbeing". This field of empirical study and theoretical development is now regarded as a substantive area of research (Baker, 2001; Wilkins and Savoye, 2009), marked by an understanding that biological factors alone are insufficient to explain either men's health or disparities with women (Robertson, 2007). Thus, Robertson (2008) argues that research should focus on how men experience and enact their health, placing in the foreground an imperative to study health in the context of masculinities and to examine its relationship to men's health-related behaviour. An increasing body of research demonstrates significant consequences to men's health outcomes of adherence to certain behaviours and norms that seem to predominate amongst men (Courtney, 2000; O'Brien, Hunt and Hart, 2005). One of the most significant theoretical contributions to conceptualising these links has been the concept of hegemonic masculinities. This identifies men's 
need to be tough, stoic and self-reliant as ways of demonstrating conformity to an idealised masculinity, and the achievement and maintenance of a superior position in a hierarchy of masculinities, as an orienting concept in the field of men's attitudes and behaviour relating to health services (e.g. Emslie et al., 2006; García-Calvente et al., 2012; Hennessy \& Mannix-McNamara, 2014; Jeffries, 2012). Evidence shows that men's adherence to the conception of idealised masculinity may account in significant ways for their health help-seeking behaviour and poor health outcomes (Banks, 2004). Despite this evidence, assumptions that hegemonic masculinity leads in a simple, linear and consistent way to poorer outcomes and less health help-seeking behaviour has come under pressure in the face of mounting evidence to the contrary (McVittie \& Willock, 2006). For instance, men may see it as perfectly tenable within a framework of hegemonic masculine identity to seek help for an experience of severe pain (Galdas, Cheater \& Marshall, 2007) when to do so is a means to retain independence by making sure one is fit enough to work, rather than it being perceived or experienced as a sign of weakness. (O’Brien, Hunt \& Hart, 2005). Nor are these complex ways of negotiating masculinity and health limited to physical conditions. As Coen et al (2013) have shown with regard to experiences of depression, some men mobilise ideals of strength and self-reliance as means for active participation in and control over the planning and implementation of their care. It is clear that how men mobilise masculinities to inform or understand their health-related behaviour is complex; this mobilisation may have dimensions related to condition and context, and 
is often characterised as an active dialogic process in which masculinity and health are mutually, simultaneously and reciprocally constructed.

A further contribution to understanding masculinities and health arises from attention to contextual factors and 'exogenous processes of social, economic and political change' (Gibbs et al, 2015). Social, economic and cultural contexts of people's lives over their lifespan have been shown to have a significant influence on their physical and mental health (Macdonald, 2006; Marmot, 2005). Social determinants are significant, extending beyond and contextualising gender.

In addition to these developments of Connell's theorisation of the relationship between masculinities and health, there has also been a call to test and refine the concept in contexts outside the Global Northwest. Indeed, Connell has suggested that in its initial formulation the concept lacked sensitivity to other cultural contexts (Connell, 2012) and has noted that much of the existing work on theorising gender and health has been very western-orientated, mainly focusing on the Global North and neither reflecting nor engaging with men from the Global South.

In this paper, we reflect on this question of how culture can be understood as a component in theorising masculinities and health. We do this via the prism of presenting findings from our study investigating how being a man in Brunei 
influences men's perceptions of and attitudes towards their health and help-seeking behaviour.

\section{The socio-cultural context of men's health help-seeking in Brunei}

Brunei is a kingdom situated on the northwest coast of the island of Borneo in South East Asia. Brunei has an area of 5,765 square kilometres and is divided into four districts namely Brunei Muara, Belait, Tutong and Temburong. Brunei has extensive resources of oil and gas but a relatively small population, and levies no tax on income. It is among the world's richest countries (Commonwealth, 2016). The population of Brunei in 2014 was 416,000 with $54 \%$ in the $20-54$ working age group; $39 \%$ are below the age of 19 while only 7\% are aged 55 and above (Brunei Darussalam: Country Report, 2011). Islam, being the national religion of Brunei, dominates and influences the everyday life of the population. About $67 \%$ of the population is Muslim (Brunei Darussalam Statistical Yearbook 2010, 2010).

Formal health care services in Brunei include private and public provision. The former are run and owned by private companies or individuals, the latter by the government of Brunei. Public Health policy in Brunei is handled by the Ministry of Health, Brunei Darussalam. Under Brunei's health policy, public health services and treatments are offered virtually free to every citizen of Brunei, whilst a minimal fee is charged to non-residents. Health service coverage is good and services provided of a 
high quality. The registered number of deaths in 2011 (Jabatan Perdana Menteri, 2011) reveal a significant disparity between male and female mortality in Brunei. According to the Ministry of Health in Brunei Darussalam (2012), the four leading causes of deaths in 2012 were cancer, heart disease, diabetes mellitus and cerebrovascular diseases.

\section{Methods and Methodological issues}

This paper reports on a qualitative study adopting a constructivist ground theory approach (Charmaz, 2014). Given our interest in investigating how men's perceptions and attitudes towards health and help-seeking behaviour were influenced by being a man in a Muslim country with a strong sense of its cultural identity, we recruited 37 men from diverse ethnic backgrounds and varied socio demographic background living in Brunei Darussalam to interviews and focus group discussions. Men were eligible to participate if they were over 18 years old, belonged to one of the major ethnic groups living in Brunei, had residency of 10 years or longer (and hence are eligible to be Bruneian citizens and, it is assumed, have been immersed in Bruneian culture) and spoke Malay or English. Men were excluded if they did not meet these criteria and in addition, if they were undergoing hospital treatment during the period of the study. 
We recruited initially from within the lead author's social network and then used purposive snowball sampling via friends, colleagues and partners. This approach was used to increase diversity amongst participants, particularly ensuring that they were from as wide an age group as possible, and from more than one of the ethnic groups within the population. When contacts were elicited we used either face-to-face meetings or social media to provide information about the study. During this recruitment phase all participants were offered the choice of participation in either an individual interview or focus group discussion. This was done to ensure that participants could choose which one they felt comfortable attending, as we were sensitive to the issue that some men may not want to discuss their health in a group setting. Materials used in individual interviews and focus group discussions (FGD) were piloted with a group of men $(n=5)$ prior to fieldwork. This took place in two waves between August and November 2015 and February and May 2016.

Five men changed their mind and withdrew from the study prior to interview. This was generally due to constraints on their time, although we noted that some seemed anxious about participation. This is unsurprising given that few participatory studies have been conducted .in Brunei and none with men. A total of 37 men participated in the study. Socio-demographic information, gathered via a short questionnaire administered at interview, is reported in table 1. Male participants' ages ranged from 18 to 76 years old. The mean age was 40 years old. In terms of ethnicity, there was a 
high proportion of Melayu (mainly Melayu Brunei) followed by Iban and Chinese and the majority of the sample are Muslim (74.5\%). Albeit, the majority (57.4\%) of participants came from Brunei Muara, there are also representatives from the other three districts in Brunei.

(INSERT TABLE 1 ABOUT HERE)

Interviews were semi-structured, drawing on previous research in line and reflecting assumptions in the constructivist grounded theory approach that we adopted about the legitimacy of the researcher having prior knowledge on an issue.. The schedule developed for the interviews covered two initial broad topics: How do Bruneian men define health and illness? What are the health help seeking processes of Bruneian men? These questions were developed with reference to concept of the health seeking process based on the work of Chrisman (Chrisman, 1977). Previous work by Robertson (2008), O’Brien, Hunt \& Hart (2005) and Galdas, Cheater \& Marshall (2005) informed how we shaped these overarching questions into questions appropriate for an interview. We also piloted the materials in order to allow us to refine or reword the questions to enhance relevance and intelligibility. This did not identify any need for major revision of wording or change in substance of the interview schedule.

The use of a semi-structured schedule introduced some flexibility into the interview allowing us to probe for information and to seek clarification of answers from 
interviewees where that felt appropriate, and also for interviewees to open up topics or concern to them

Three focus groups were conducted with a total of twelve men. A total of twentythree of men participated in individual interviews. .

Our motives for choice of methods rested on our interest in obtaining, exploring and interpreting and accounts of experience capable of giving us a deep understanding of the issues, characterised by a focus on the meanings attributable to the population being researched. It has been suggested interviews are the most appropriate and principal means of data collection in this context (Greenhalgh, 2006). The addition of the focus groups was intended to enrich the data gathered through individual interviews. They provided a means to see the way that men talk to each other about these issues and also react to views expressed within a male group. These dataformed a more naturalistic insight into men's experiences and views of health and helpseeking.

Interviews and focus groups s were conducted in Malay, English or a combination of both languages by the lead author, who is an indigenous Bruneian man, 
All participants were assured of their anonymity and confidentiality as part of the process of securing active, informed consent. Participants were interviewed at a venue of their choice. All interviews were audio-recorded with participant's permission, transcribed verbatim and manually coded. Pseudonyms have been employed for all the interview excerpts included in this paper in order to maintain anonymity. These pseudonyms are the names of men commonly and widely found in Brunei.The study was approved by a UK university ethics committee.

All data analysis was undertaken on verbatim transcripts of interviews and focus group discussions, that is, with the material retained in the original languages used by participants (a mixture of English and Malay languages). This approach was adopted in order to avoid loss in meaning due to translation (Van Nes et al., 2010). Only once the analysis was complete were findings translated for the purpose of reporting. Analysis involved an iterative process of coding the texts, then working up themes that were comprehensive, exhaustive and explicative of the data, following the principles of constructivist grounded theory. This paper focuses on the main themes that emerged from interviews with Bruneian men concerning the relationships between masculinities, men's health and well-being and how these intersect with key temporal transitions across the life course. We have rendered the themes and their relationship in Figure 1. The figure illustrates that our overall emerging theme concerns being healthy and performance of an idealised Bruneian masculinity. This 
captures that key idea emerging from our data that the ways that study participants think about health and help-seeking, is locked into a mutually constitutive relationship with the way that they see themselves living under a cultural requirement to envision and enact their masculinity through a series of age-related roles in relation to the family. To the right of the figure we present the stages of phases of life which study participants indexed in mapping this life-course. To the left of the figure we show running alongside this the other major theme concerning the body and its place as marker, symbol and mode through which health is experienced and expressed. Men referenced the body throughout the life course pointing to it as, for example, the place where their strength to discharge physical tasks and chores resides and hence waxing and then waning with adulthood and old age, respectively.

[INSERT FIG. 1 ABOUT HERE]

\section{Findings}

We first consider the way that the body is located in life course, which reflects the way that this topic was an entry point into men's accounts of masculinities, role and health. 


\section{Being healthy and performing an idealised Bruneian masculinity}

It is apparent from the data that whilst health is important for Bruneian men, they are, like men in other cultural contexts, reluctant service users (Galdas et al., 2005; O'Brien et al., 2005). Men reflected on health and help-seeking in terms of the construct of masculinity as requiring them to be independent, self-reliant, robust and tough (Courtney, 2000). Consistent with other research, this talk about health and masculinity was often indexed in terms of the body as a determinant and indicator of health and well-being (Kimmel \& Messner, 1998).

\section{The body as an entry point to masculinities, health and the life course}

Generally, when asked to define health, men in this study focussed on their body, talking about wanting to be fit, for example in order to play football, but also wanting to be seen as fit by others, in this way performing masculinity through their healthy bodies.

For me, you know, I play sport a lot, all the time and sometimes go to the gym. That's how I keep my health, you know I'm a footballer, if I have good body, like, you know our team, we all are fit so one time we have football match, we managed to intimidate our opponents just by them looking at our body, we all physically fit, they will think we are hard to defeat

(Khalid, 19 years old). 
What emerged as especially significant, however, was that the way that the 'fit' body, construed as a signifier of health, was highly and explicitly embedded in what was presented as a cultural and nation-context specific conceptualisation of the male role in public and private life. Men largely articulated this in relation to the family. Moving from being a good son to a 'good' husband, then a 'good' father and finally a 'good' grandfather was reported as the ideal sequence of roles and transitions that Bruneian men expect to make over their life course. These different phases of their life course are associated with certain roles and responsibilities, which they as men are required to perform and discharge. These are identified as attributes of their masculinity and regarded as socially normative in Brunei. According to study participants, meeting these expectations and fulfilling these responsibilities will make them 'good, responsible Bruneian men'. We argue that it is appropriate to refer to these as aspects of "Bruneian masculinities" when applied to consideration of health and help-seeking. We do this in order to make a clear a distinction (albeit as we shall show, not without overlap) from other masculinities, particularly from the Global North.

Bruneian life course, masculinity and health 
Participants discussed the expectations that were placed on them throughout their life course; the ability to perform these masculine expectations and responsibilities was important, and could only be fulfilled with the presence of good health.

We as men, have lots of responsibilities, so being healthy is very important

(Mohd, 29 years old, single).

\section{Being a good son}

Young single men $(\mathrm{n}=10)$ discussed wanting to support their parents financially after finishing their studies, and the importance of securing a good job in order to enable them to do this. They also described the importance of being successful in their studies, thereby bringing pride to their family. Educational success, achieving job security and being able to provide for their parents were all components of the idealised view of what makes a good son, and also provided them with a kind of 'road map' through the early part of their lives. Most young men had a view of what their future looked like and what it would involve in terms of familial and social functions. This can be understood as a way for young men to manage and imagine their futures which helps to prepare them for their transitions and make sense of the present and past (Thomson and Holland, 2004).

Younger single participants $(n=8)$ also talked about how being single allowed them 
to focus on building and preparing for their future for themselves, their parents and future family. They explained the importance of health in allowing them to study hard, which in turn would lead to a good job which would enable them to continue supporting their parents and eventually get married and look after their own family.

If you are healthy you can study better, pass university, get a good job, earn good money then you can help your parents and build your own family, get married.

(Taufiq, 25 years old, student).

I just want to study hard, get a good job and then make my parents happy, make them proud, look after them, support them, help them...it's my responsibility, they are getting old now and I'm their son

(Bakar, 23 years old, single).

Honouring and providing for parents was significant for these men. To do this by financial means was the norm; however, some young men compensated for a reduced capacity to provide financial support by contributing in other material ways, for example, by helping with everyday household routines. As Abdullah (38 years old, single), who felt that he lacked the financial capacity to contribute, explained: 
Mum's old now...so I help by driving her to shops and I help to carry her groceries

And, Daud (32 years old, married), who said,

My family (wife and children) is my responsibility but so are my parents... if I have extra cash I will give them some or buy them foods. Otherwise I help in other ways like anything they needed help with at home.

These men also pointed out it is a norm for Bruneian children, both sons and daughters, to take care of their parents and it is seen as a way of expressing gratitude and showing appreciation for the care that they received in their childhoods. This social practice and expectation is long-lived as was evident when older men in the study referred to the same onus falling on them when they were young, some 40 years earlier. As Syafie (65 years old, retired), reflected:

That's how it is, they looked after us when they were younger, now it's our turn to look after them.

It must also be noted that that even though the responsibility to look after parents is equally placed on sons and daughters, this expectation changes after a daughter 
marries in Brunei, because when she marries her responsibility is seen as primarily towards her husband and children.

The responsibility for looking after parents continues even after a son has got married and moved out to live with his wife and children, as Daud said:

I live in the city now with my family because it is easier for me to go to work, but I go to their house a lot to see them or at least phone them just to make sure they are alright.

It may be that wider socio-cultural change in terms of the way that families live moving away from life-long residency under one roof or in very close physical proximity - means that the focus on financial provision for parents is gaining a higher status and importance for young men than providing personal, material care. Indeed, the introduction of an affordable housing scheme by the government of Brunei (Jabatan Kemajuan Perumahan, Kementerian Pembangunan Brunei Darussalam., 2016) may be driving this move to independent living whilst the small size of the country and population density means that regular close contact is not necessarily entirely ruled out.

Men also believe that looking after their parents is commensurate with and required 
by Islam:

Of course I will look after my parents, you know when they get old. When I finish my study and start to work, I will look after them. Make them happy, they brought me up well, without them I wouldn't be here. For me as a Muslim guy you know its important and its 'pahala' too

(Bakar, 23 years old, single).

'Pahala', which Bakar mentions, refers to good deeds in Islamic teaching, which are seen as a responsibility and a way of saying 'thank you' to parents. Moreover, taking care of parents is also a responsibility warranted by the government of Brunei, and failure to do so can lead to legal action being taken against an adult who does not support his or her parents despite having the means to do so. This is as per Islamic Family Order, section 184 of the Syariah law (Mat Sani, 2016).

\section{Being a good husband and father}

Having good health continues to be significant in what men described as the second stage of the male life course, as husband and father, where their priority becomes providing a comfortable life for their family by working hard and earning money. Married men talked about perceived societal expectations that they would be a good husband by financially supporting the family, which was usually framed in terms of 
paying the bills, buying food and providing shelter for their wife and children. They felt that this role of provider could only be achieved with good health:

Health is important for me. If you not feeling well, how do you go to work? Who will support my wife and kids?

(Isa, 30 years old, married).

It was in the context of the family that the notion of 'man as leader' emerged. Men constructed this to mean not only being the leader of the family but also the acquisition of social status outside it as someone who led a family. This linked back to health because discharge of leadership required physical wellbeing.

You must look after yourself because you're the leader of the family. If you're sick you can't look after your family

(Yusof, 60 years old, married).

This healthiness enabled men to work in gainful employment so as to provide financially, but they also talked about helping their wives to look after the home, particularly when it came to doing physically demanding tasks which were regarded as more challenging and less appropriate for women to engage in. 
All the heavy work, at home, like carrying heavy stuff, like that. I will do that not my wife; she will do other house work, like cooking.

(Khalil, 37 years old, married).

The men foreground physical labour as the form that their contribution to household tasks takes, reemphasising the centrality of the body and physical strength to performance of conventional and culturally appropriate Bruneian masculinities.

\section{Adulthood, marriage, intimacy and health}

Daud, a 32 year old married Muslim man with three children, explained that as a married man, he is not only responsible for contributing in terms of physical work and financially to his family and parents, but also as a husband he has a responsibility to fulfil the sexual needs [Batin] of his wife. Again, according to him, good health is demanded in order to be able to do this.

You know...money...home...food...help at home...That's Zahir needs...but there is another aspect as well...the Batin needs...that is also your obligation as a husband...in Islam we are being taught about that as well...health is important for that 
A similar discussion arose in the interview with Samsul, a 60-year-old divorcee and Najib, a 68-year-old man who had got married for the second time, five years ago, to a much younger woman.

Najib: Every man wants a wife so we can do it [here he is referring to sexual intercourse] if he wants "it" so he has to get married. That [sex] is important for men and women too. We human beings but especially for husband, he has his wife, that makes it become more important.

Samsul: That's true.

Najib: Its important for men, Allah creates us, human beings with needs. With Allah's will, it is still able to function for you so use it because you are healthy. But sometimes I feel sorry OK even some young men can't do it, no chance! [bending his finger]. This means they are not healthy. If a man can get this [showing his straightened finger] that's the sign to fulfil your needs but if you cannot get it, no use being a man.

For these married men, their sexual relationship with the wives is clearly significant as a marker of health. It also seems to meet cultural and religious requirements associated with responsibilities of men as husbands. It may also be helpful to note at 
this point, that because of the social and legal censure around pre-marital sex in Brunei, talking about sex does not have the same cultural significance in terms of establishing and demonstrating masculinity as it does in more secularised western contexts and may be less openly discussed outside the framework of Islam (Al-Sayf, 2007).

\section{Being a good grandfather}

Interviews with five older men, all of whom were over 60 years old and retired, revealed a significant difference in terms of how they configured masculinity and health. At this point in the life course these men were no longer working and their roles had shifted from being a provider and leader to being a grandfather. Bruneian grandfatherhood is quite distinct from fatherhood in a number of respects. Firstly, work no longer figured in these men's lives. Secondly, they are men of an age when ill health and loss of some physical capacity is starting to become a strong possibility or indeed reality. Thirdly, responsibilities become focussed solely on the home and family now they are no longer employed.

These men talked about their routine at home such as looking after grandchildren, taking them to and picking them up from school. Three of these five grandparents lived together with their children and grandchildren. Those living separately still helped out with such duties. In this case, the grandparents would pick up and take 
their grandchildren to and from school, and bring them to their home. Their parents then picked them up from their grandparents after work. These grandfathers felt that it was important for them to do this, thus contributing to the running of the household, since they were no longer working outside the home. Involvement was often enabled because, although somewhat on the decrease, three generation households are not unusual in Brunei. Men at this age valued the time with their family, and talked about wanting to be home helping their wives, children and grandchildren. They described themselves as required at home, which could be interpreted as being 'required' meaning they can feel valued. For these men, becoming ill could disrupt their routines and contributions to the family, and thus endanger this sense of value.

With advancing age, possible infirmity, and retirement from work, these men were carving out new roles in order to give themselves an identity and create an important place in the family structure.

Now I am no longer working, just stay at home, help my wife with the household chores and help my children to send their kids to and from school...all my kids are busy working, it is hard for them to pick up their children from school so I just help them. At least I can do something for them.

(Ramli, 66 years old) 
When opportunities to be the provider are reduced or cut off, in this case by their retirement due to age, such helping enables these older men to make sense of the cultural requirement to play a valuable and clear gender-specific role in the family.

These men said that if they fell ill it could disrupt their capacity to contribute to family life and cause trouble and inconvenience to the family, and this would be worsened if they had to be hospitalised. Indeed, it seemed that older men almost dreaded hospitalisation; one feature of a marked reluctance to use health services, especially to contact a doctor, was a concern that they would found to be seriously ill in ways of which they were unaware, and then as a result, confined to hospital. They thought this was probable since they perceived that their age meant that they were likely to have some health problems. Younger men were also very aware of this and some gave accounts of how their fathers had been challenged by ill-health and were anxious about being hospitalised.

My dad, he does not want to go to hospital. He is afraid the doctor will admit him to the ward. He don't like it in the ward. He will be worried about lots of things, you know, his grandchildren, picking them up from school

(Yusof, 60 years old, married).

And, Samsul (60 years old, married) commented: 
If you go to hospital surely there will be many things the doctor will tell you. You know all sorts of health problem, your heart, this and that, you know.

Here we can see how older men still find it is important for them to contribute despite no longer working but they contribute in other means such as helping with household chores. For this, good health is considered as paramount importance, as previously discussed.

\section{Discussion}

In this paper we have explored how experience and expectations of the male life course in Brunei relate to ideas about male roles and responsibilities and are coconstructed with ideas and behaviour associated with health. This is the first study of its kind to be undertaken in Brunei, a small, rich country in South-East Asia with an emerging public and policy awareness of gender disparities in health outcomes and behaviour, including service use.

The study does have some limitations, which to some extent reflect its novelty and point, we would argue, towards important new areas for research. It is well known that all methods adopted in qualitative research have potential strengths and weakness and that reflexivity is a valuable tool that may be used to identify and evaluate and to 
better understand the data and inform their analysis (Hammersley and Atkinson, 2007). We are very conscious that we faced a risk that men's responses to this study, regardless of method adopted, might be inflected by a degree of social desirability. Indeed, the absence of significance major deviance in the data from the core views and ideas does seem quite striking when contrasted with what might be expected in some other cultural contexts. This we have considered, and believe that it might be in part down to the nature of the sample, although indications that men who declined to take part did so for practical reasons or concern about research participant rather than subject matter. Nevertheless, we suggest that future research might target men from those ethnic and other groups present in Brunei but under-represented in this study. For example men who identify as Chinese or perhaps, notwithstanding the potential risks, as non-binary or not exclusively heterosexual. This would provide both a means by which to test the apparent power and wide understanding of the cultural narrative about masculinities and health that we have identified in this study, and also identify its limits and where it might be a constraint. We also note that the research team centred around this paper's lead author who is a Bruneian man, along with a British woman and man. This we believe was productive in checking on cultural assumptions and possible recognition and misrecognition of data and their possible meaning. In practice, because our Bruneian colleague did the fieldwork, he was required, by necessity, to surface and make explicit what might otherwise have remained assumed knowledge and experience, because we did not share that cultural background. 
What we have shown is while Brunei is culturally highly distinctive, and perhaps even more importantly, that men involved in this study feel that it is culturally distinctive, with a locally specific and meaningful idealisation of male roles, relationships and responsibilities within and outside the family, it is clear that much of what they say and describe is recognisable from research with men in other contexts, in both the global south and north. For example, the indexing and mobilisation of the body, and specifically the 'fit' body, as an indicator and means of displaying health and its importance as a marker of masculinity has been found in Ireland and East Africa (Hennessy \& Mannix-McNamara, 2014; Silberschmidt, 2004). Bruneian men’s evident concern about formal health services, manifest in this study in terms of concerns about being hospitalised, is resonant with other research conducted in the USA reflecting both concerns about the risk of being removed from the support of family and scepticism about medical authority (Green \& Pope, 1999; Meissener et al, 2006).

Nevertheless, examining how these higher order findings - the significance of the body, and concerns about demonstrating and maintaining independence - are understood by Bruneian men in terms of a sense of national culture, and the material context that this provides links the enactment of masculinity at the level of the individual to social norms and structures in ways that demand we pay attention to 
local socio-cultural terrain. Below we allude to some of these factors and also suggest how they might be influential.

\section{The health system and public and private medicine.}

Expectations of the public system were widely regarded as a barrier to health helpseeking. Men reported long waiting times, in poor physical environments and perceived the risks of over or under-diagnosis. A frequently heard complaint was that one waited for hours only to be prescribed paracetamol (Panadol), which could be bought over the counter anyway. However, they might also actively seek access to professional healthcare advice when it suited them for other reasons. Notably, the private system was often spoken about as a way to get a medical certificate - a means to demonstrate real illness in order to explain absence from work. Men would often mobilise the same argument in relation to masculinities with respect to these quite different courses of action, namely that the first (not using a public system) was about retaining independence and agency as befits a man, and that the second (using the private system) also allowed them to show a powerful form of masculinity because they could evidence via the medical certificate that they were not malingering or 'weak'.

Traditional medicine. 
Older men, and particularly those living more rurally and remotely from health services and population centres, discussed the use of traditional, usually herbal, treatments, remedies and diets to protect health. This is known in Brunei as 'Ubat kampong'. That older men spoke about this may reflect the fact their longevity means that they have experience of life prior to the development of the comprehensive, free health system in Brunei. For many of these men the 'old ways' had not been superseded by the new biomedicine and health services, remaining legitimate, valuable and effective means of looking after one's health, albeit, they felt that knowledge and awareness of these medicines was dwindling away amongst younger generations. The use of traditional medicine was explicitly linked to masculinity by these men in terms of a perceived male responsibility for growing and knowing about which plants to use and their preparation. This would seem to suggest that knowledge about the natural world, generationally handed down, was an aspect of Bruneian masculinity which tied male role, knowledge, authority as provider, and carer to personal, family and community health.

\section{Bruneian Islam and 'Ikhtiar'.}

As the findings regarding sexuality show, the importance of Islam on men's conceptualisation of health and motivations and meaning making around health helpseeking was very evident from the interview data. In fact it saturated many of the themes as an underpinning orienting moral, spiritual guide to men's social practices 
around health. A particularly significant concept, which has a locally specific meaning, is 'Ikhtiar'. It is not a straightforward matter to transliterate this concept but broadly it conveys an ideal and idea of self-reliance. Ikhtiar has some impact on health with parallels to the desire for independence shown to be valued by men in the west (Boman \& Walker, 2010; Galdas et al., 2007; Johnson, Oliffe, Kelly, Galdas, \& Ogrodniczuk, 2012) whereby, men expressed the need to be self-reliant as a way of conforming to masculine identity and consequently, delay seeking health care. However, Ikhtiar has associations with cultural and religious practice that is locally very significant and regarded by men as 'Bruneian'.

To some extent this is framed by deeper meaning of Ikhtiar which literally means 'to initiate', 'to attempt' or 'making an effort', which is not exclusive to health helpseeking behaviour. The term can be used in other contexts as well.

The importance of Ikhtiar can be seen as a factor militating against Bruneian men accessing help. Ikhtiar seems most importantly to provide a way of acknowledging illhealth, responding to it and negotiating the tensions between potential perceptions of weakness attached to help seeking and undermining of independence and social roles which are so important to Bruneian men. This study contains some evidence suggesting Ikhtiar is a way men can in fact negotiate ill-health use and show adherence and conformity to the demands of masculine identity. They equated being 
able to initiate self-care and not turning to others for help as a positive masculine attribute. They also saw it as evidence that they are 'tough' enough to face the real world and fulfil the demands they shoulder as men.

The interviews also demonstrated the usage of terms like "manja" [literally 'wimp'] to describe men who 'give up' by seeking help too soon, without trying to solve the problem themselves first. Lacking Ikhtiar and being manja is seen as being weak, but as men cannot be weak because they are [or will be] the leader of their family, being manja is an unmasculine, and hence undesirable, behaviour. Independence and strength are desirable leadership characteristics, enabling men to perform expected masculine obligations, including working hard, earning money and looking after the family.

Islam and especially 'Ikhtiar' are central to our analysis of the significance of cultural context in understanding how the first order ideas invoked by hegemonic masculinities are mobilised in Brunei, demonstrating how individual male experience and identity work connects health to social practice, the proximal realm of familial relationships and responsibilities and to state power and indeed divine ordination and the grand stage of universal ordering provided by faith. This is consciously done by men in Brunei through these layers at which Islam reaches through and beyond the 
individual. This would seem to contrast in important ways to influence felt by men on masculinity and health in the much more secularised north western hemisphere.

We pointed at the outset of this paper to the attention being paid to exogenous influences on masculinities, and we return to that issue wanting to acknowledge both the impact of globalising influences, and some influences local to South-East Asia. For example, our interviewees mentioned 'Movember' the annual promotion of men's awareness of, particularly, testicular cancer. Such globalising movements which begin to suggest similarities between men around the world, and particularly perhaps personal responsibility and agency on behalf of the self, are counter-balanced by evidence showing the continuing and very high importance of masculine identity conceived of as less individual and more relationally created especially through the family. The importance attached to the family and male role through the life course echoes for instance, that of an earlier study undertaken in Malaysia that aimed to explore men's perceptions about health and illness and factors affecting their health and illness behaviour (Yun et al., 2008). This research with men in Malaysia revealed that family and the need to continuously look after their family both financially and physically, was also a major motivation for them to stay healthy.

It is on this basis that we argue, therefore, that this study begins to provide an empirical base on which to be able to develop two things: both a conceptualisation of 
men, health, masculinities and health help-seeking relevant to Brunei which foregrounds the life course; and, second, an elaboration of the detail which it has been argued is required to develop the a nuanced conception of hegemonic masculinities in contexts outside the global northwest. For Bruneian men being healthy is about being fit judged by their ability to go through all the transitions in their life course and perform all the expected roles and responsibilities that come with it. All these transition and roles are mapped out for them, passed from generation to generation.

\section{Conclusion}

In this paper we have reported one of the major findings from the first study of men's attitudes towards health and health help-seeking undertaken in Brunei. We have reflected on our findings in terms of the call articulated by Raewyn Connell to test and develop the concept of hegemonic masculinities in relation to health outside the Global North West.

We conclude that the central idea of the power of an idealised masculine identity to orient men's attitudes and behaviour in relation to health and their accounts of those attitudes and behaviour is applicable and, moreover, that some of the key features that make up that ideal are resonant in Brunei as has been shown elsewhere. With reference in particular to the notion of a mutually constitutive relationship between life-course, masculinity and health, we have illustrated and accentuated the 
significance of the local cultural terrain and the possibilities that it presents for mobilising health and maleness. Family, faith and a sense of Bruneian identity figure most predominantly as features of this terrain. What this implies is that the 'local' in these respects and perhaps others, is important in trying to understand and therefore in order to intervene in the health of men. In theoretical terms, what 'grand' theory such as hegemonic masculinities requires, and can accommodate is nuance and detail which can be introduced through a socio-cultural approach to understanding men, masculinities and health. 


\section{References}

Al-Sayf, S. K. (2007) Islam today: Sexual rights in marriage., Islam Today. Available at: http://en.islamtoday.net/artshow-403-3384.htm (Accessed: 14 October 2015).

Baker, P. (2001). The international men's health movement. British Medical Journal. 323 (November), 1014-1015.

Banks, I. (2004). New models for providing men with health care. Journal of Men's Health and Gender. 1(2/3), 155-158.

Boman, E. K. O., \& Walker, G. A. (2010). Predictors of men's health care utilization. Psychology of Men \& Masculinity, 11(2), 113-122.

Brunei Darussalam: Country Report. (2011). Bandar Seri Begawan. Retrieved from http://www.mhlw.go.jp/bunya/kokusaigyomu/asean/2011/dl/Brunei_CountryReport.p df

Brunei Darussalam Statistical Yearbook 2010. (2010). Bandar Seri Begawan.

Chrisman, N. (1977) 'The health seeking process: An approach to the natural history of illness.', Culture, Medicine and Psychiatry., 1(4), p. 351-377.

Charmaz, K. (2014) Constructing Grounded Theory. (2nd Edn.). London: Sage Publications Ltd.

Coen, S. E., Oliffe, J. L., Johnson, J. L., \& Kelly, M. T. (2013). Looking for Mr. PG: Masculinities and men's depression in a northern resource-based Canadian community. Health \& place. $21,94-101$. 
Connell, R. (2012). Gender, health and theory: conceptualizing the issue, in local and world perspective. Social science \& medicine. 74(11), 1675-1683.

Courtney, W. H. (2000). Constructions of masculinity and their influence on men's well-being: a theory of gender and health. Social Science \& Medicine (1982). 50 (10), $1385-401$.

Commonwealth. (2016). Brunei Darussalam: Economy. Retrieved November 17, 2016, from http://thecommonwealth.org/our-member-countries/bruneidarussalam/economy.

Emslie, C., Ridge, D., Ziebland, S., \& Hunt, K. (2006). Men's accounts of depression: Reconstructing or resisting hegemonic masculinity?. Social Science and Medicine. 62, $2246-2257$.

García-Calvente, M. D. M., Hidalgo-Ruzzante, N., Del Río-Lozano, M., MarcosMarcos, J., Martínez-Morante, E., Maroto-Navarro, G., ... Gil-García, E. (2012). Exhausted women, tough men: A qualitative study on gender differences in health, vulnerability and coping with illness in Spain. Sociology of Health \& Illness. 34(6), 911-26.

Galdas, P., Cheater, F., \& Marshall, P. (2007). What is the role of masculinity in white and South Asian men's decisions to seek medical help for cardiac chest pain?. Journal of Health Services Research \& Policy. 12(4), 223-9.

Galdas, P. M., Cheater, F., \& Marshall, P. (2005). Men and health help-seeking behaviour: literature review. Journal of advanced nursing. 49(6), 616-623. 
Gibbs, A., Vaughn, C. and Aggelton, P. (2015). "Beyond ' working with men and boys' : redefining, challenging and transforming masculinities in sexulity and health programmes and policy. Culture, Health \& Sexuality. 17(Sup2): 85-95

Green, C.A. and Pope, C.R. (1999). Gender, psychosocial factors and the use of medical services: a longitudinal analysis. Social science \& medicine. 48(10): 13631372.

Greenhalgh, T. (2006). How to Read a Paper: The Basics of Evidence-based Medicine (3rd Edn.). Oxford: Blackwell Publishing.

Hammerlsey. M., \& Atkinson, P. (2007) Ethnography: Principles into Practice. Third Edition Routledge: London.

Hennessy, M., \& Mannix-McNamara, P. (2014). Gendered perspective of men's health and health seeking: Implications for public health and health promotion. International Journal of Medical and Health Sciences Research. 1(2), 13-28. Jabatan Perdana Menteri. (2011). Brunei Darussalam Statistical Yearbook 2011. Jabatan Perangkaan.

Jeffries, M. (2012). “Oh, I'm just, you know, alittle bit weak because I'm going to the doctor's: Young men's talk of self referral to primary healthcare services".

Psychology \& Health. 27(8).

Johnson, J. L., Oliffe, J. L., Kelly, M. T., Galdas, P., \& Ogrodniczuk, J. S. (2012). Men's discourses of help-seeking in the context of depression. Sociology of Health and Illness. 34, 345-361. 
Kimmel, M., \& Messner, M. (1998). Men’s lives. (3rd Edn.). Toronto: Allyn \& Bacon.

Macdonald, J. (2006). Shifting paradigms: A social determinants approach to solving problems in men's health policy and practice. MJA. 185, 456-458.

Marmot, M. (2005). The social determinants of health inequalities. Lancet. 365, 1099-1104.

McVittie, C., \& Willock, J. (2006). "You can’t fight windmills": How older men do health, ill health, and masculinities. Qualitative Health Research. 16(6), 788-801. Meissner, H.I., Breen, N., Klabunde, C.N. \& Vernon, S.W. (2006) Patterns of colorectal cancer screening uptake among men and women in the United States. Cancer Epidemiology and Prevention Biomarkers. 1;15(2):389-94.

Mat Sani, K. (2016). 'It is compulsory to provide nafkah for your parents'. The Brunei Times, 12 June. Available at: http://www.bt.com.bn/newsnational/2016/06/12/\%25E2\%2580\%2598it-compulsory-provide-nafkah-yourparents $\% 25 \mathrm{E} 2 \% 2580 \% 2599$.

O’Brien, R., Hunt, K., \& Hart, G. (2005). "It's caveman stuff, but that is to a certain extent how guys still operate': Men's accounts of masculinity and help seeking. Social Science \& Medicine. 61(3), 503-16.

Silberschmidt, M. (2004). 11. Masculinities, Sexuality and Socio-Economic Change in Rural and Urban East Africa. Re-thinking sexualities in Africa. 233.

Robertson, S. (2007). Understanding men and health: Masculinities, identity and well 
being. Berkshire: McGraw - Hill.

Robertson, S. (2008). Theories of masculinities and men's health-seeking practices. Nowhere Man Press.

Rosenstock, I.M. (2005). Why people use health services. The Milbank

Quarterly. 83(4).

Thomson, R. \& Holland, J. (2004) Youth Values and Transitions to Adulthood: An empirical investigation. Edited by Families \& Social Capital ESRC Research Group. london: London South Bank University. Available at: http://teaching.mdu.edu.tw/datacos/09420122025A/Youth Values And Transitions.pdf.

Van Nes, F., Abma, T., Jonsson, H. and Deeg, D. (2010) 'Language differences in qualitative research: Is meaning lost in translation?'. European Journal of Ageing. 7(4), pp. 313-316.

Vienne, M. (2015). Brunei: From the Age of Commerce to Rentier State. Singapore: NUS Press Pte Ltd. Retrieved May 18, 2018, from Project MUSE database.

World Health Organization. (2000). What about the boys?A literature review on the health and development of adolescent boys. Geneva. Retrieved from http://apps.who.int/iris/bitstream/10665/66487/1/WHO_FCH_CAH_00.7.pdf Wilkins, D., \& Savoye, E. (2009). Men's health around the world a review of policy and progress. Brussels. Retrieved from http://www.mhfs.org.uk/documents/EMHFIMHPR-final.pdf. 
Yun, L. W., Meng, T. H., Jenn, N. C., Fah, T. S., Ming, K. E. and Ping, W. L. (2008)

About men's health: Views from Mars and Venus. (1st Edn.). Selangor Darul Ehsan:

Malaysian Society of Andrology and the study of ageing male. 